\title{
Specificity of auditory implicit and explicit memory: Is perceptual priming for environmental sounds exemplar specific?
}

\author{
CHUNG-YIU PETER CHIU \\ Harvard University, Cambridge, Massachusetts
}

\begin{abstract}
Previous research (Stuart \& Jones, 1995) has suggested that identification of environmental sounds may be mediated by abstract sound recognition units. This article reports the results of four repetition priming experiments that find evidence to the contrary. Participants attempted to identify environmental sounds from the initial sound stems (Experiments 1 and 2) or when the sounds were embedded in white noise (Experiments 3 and 4). Repetition of an identical exemplar sound led to more priming than did exposure to a different exemplar, provided that the perceptual difference between the two different exemplars was sufficiently large. Such an exemplar specificity effect was independent of the depth of prior encoding. A similar exemplar specificity effect was also found in explicit stem-cued recall (Experiments 1 and 2) and recognition (Experiment 3). Depth of encoding dissociated performance on tests of repetition priming and explicit memory. These results suggest that a significant amount of specific information is remembered, both implicitly and explicitly, to characterize individual exemplars of a sound category.
\end{abstract}

The distinction between perceptual repetition priming and explicit memory has received considerable theoretical and empirical scrutiny in recent years. In contrast to explicit memory, which involves conscious recollection of the study episode, perceptual priming reveals itself as a facilitation or bias in task performance as a result of a prior learning episode, without necessarily involving conscious recollection. Characteristics of perceptual priming that consistently set it apart from explicit memory include its preservation in patients with organic amnesia and its insensitivity to semantic versus nonsemantic encoding (for reviews, see Chiu \& Schacter, 1995; Roediger \& McDermott, 1993; Schacter \& Buckner, 1998; Schacter, Chiu, \& Ochsner, 1993; Squire, 1994; Tenpenny, 1995). Recent research has focused on the third characteristic of perceptual priming that supposedly distinguishes it from explicit memory, which is its sensitivity to changes in physical features (e.g., visual to auditory, words to pictures) of the stimuli between study and

This research was supported by National Institute of Mental Health Grant RO1 MH45398-01 A3 and National Institute on Aging Grant RO1 AG08441 awarded to Daniel L. Schacter. This work is based on a doctoral dissertation submitted to the Department of Psychology at Harvard University. I am very grateful for the advice I received from the members of my dissertation committee, Daniel Schacter, Nancy Kanwisher, Alfonso Caramazza, Gerald Kidd, Michelle Lichtman, and Richard Hackman. I gratefully acknowledge the assistance of Jim Ballas for access to his SoundIdeas sound library, members of the Harvard memory lab for stimulating discussions, and Wilma Koustaal, Chris Chabris, Lana Israel, and Craig Hamson for experimental assistance. Correspondence concerning this article should be addressed to C.-Y. P Chiu, Department of Psychology, University of Cincinnati, P. O. Box 210376, Cincinnati, OH 45221-0376 (e-mail: peter.chiu@uc.edu) test. Here, however, the evidence is considerably more mixed, especially for changes in physical feature within the same stimulus modality. First, repetition priming may be perceptually specific to some stimulus features, but not to others. For instance, repetition of a visual object consistently produces more priming than does repetition of a different exemplar from the same object category (see, e.g., Biederman \& Cooper, 1991; Srinivas, 1993). However, changes in the size, location, and left-right orientation of an object do not affect priming (e.g., Biederman \& Cooper, 1991, 1992). Second, explicit memory may show as much or even more perceptual specificity as in repetition priming under certain conditions. For example, explicit memory can be adversely affected by a change in the speaker's voice, as in repetition priming (e.g., Goldinger, 1996; Luce \& Lyons, 1998; Palmeri, Goldinger, \& Pisoni, 1993; Sheffert \& Fowler, 1995). Changes in size, left-right orientation, and color of visual objects can have an adverse effect on recognition memory without affecting priming (e.g., Cave, Bost, \& Cobb, 1996; Cooper, Schacter, Ballesteros, \& Moore, 1992). Third, whether repetition priming shows sensitivity to a particular stimulus feature may depend on the details of the experimental conditions. Some studies on visual word priming reported a reduction in priming following a change in case or typefont (e.g., Blaxton, 1989; Curran, Schacter, \& Bessenoff, 1996; Graf \& Ryan, 1990; Koivisto, 1995; Marsolek, Kosslyn, \& Squire, 1992), but others did not (e.g., Carr, Brown, \& Charalambous, 1989; Rajaram \& Roediger, 1993). Changes in the speaker's voice led to less auditory word priming in some studies (e.g., Goldinger, 1996; Schacter \& Church, 1992; Sheffert, 1998), but not in others (e.g., Jackson \& Morton, 1984; Luce \& Lyons, 1998). 
The present study focuses on the specificity of repetition priming of environmental sounds (e.g., telephone ringing, clock ticking, footsteps, etc.). Three recent studies have examined environmental sound priming, and their results suggest that sound priming is mediated by domain-specific representations. For example, hearing or seeing the sound names produced no appreciable amounts of cross-modal priming in environmental sound identification (Chiu \& Schacter, 1995; Stuart \& Jones, 1995), whereas forming mental images of the sounds led to small but significant amounts of priming (Stuart \& Jones, 1996). Semantic encoding and nonsemantic encoding led to equivalent levels of priming (Chiu \& Schacter, 1995). Interestingly, a different exemplar of the same type of sounds (e.g., a different door bell) primed subsequent sound identification to the same extent as did the identical exemplar (Stuart \& Jones, 1995). Stuart and Jones (1995) postulated the existence of highly abstract, but domain-specific, sound recognition units called audiogens. According to this hypothesis, audiogens mediate sound priming and are activated to the same extent by different exemplars of the same sound category.

That environmental sound priming does not show exemplar specificity is quite unexpected. Previous research suggests that the poorer the match in perceptual features for the priming and the test stimuli, the more likely it is that priming will exhibit perceptual specificity. Different sound exemplars represent an extreme case in which few acoustic features are shared, and yet in this case priming is not perceptually specific. More important, exemplar changes have consistently produced a reduction in visual object priming. Because most theories of priming, such as the perceptual representation system account proposed by Schacter and his colleagues (e.g., Schacter, 1994; Schacter et al., 1993) or the transfer-appropriate processing account proposed by Roediger and his colleagues (e.g., Blaxton, 1989; Roediger \& McDermott, 1993), subscribe to the view that transfer depends only on the goodness of match between encoding and retrieval processing, it is unclear how these different theories can provide a principled explanation for the difference in specificity effects in priming across stimulus domains. Stuart and Jones's (1995) finding deserves close scrutiny because it may suggest a fundamental difference in the way in which memory representations are organized for environmental sounds, as compared with other stimulus classes.

In Stuart and Jones's (1995) procedure, participants at encoding were given environmental sounds, were asked to generate names for the sounds, and then were required to count the number of syllables in each name. At test, the environmental sounds were presented to the participants for identification at a level below threshold. When the participants failed to identify the sound, the level was increased in small steps, and the procedure was repeated until identification was achieved. Closer inspection of this method suggests that at least four factors deserve consideration before firm conclusions can be drawn. First, this procedure of ascending limits may be undesirable because it tends to promote guessing and/or involvement of voluntary or involuntary explicit memory. Second, when sounds are presented at a level close to threshold, physiological noise tends to dominate and render the task more similar to identification in noise, which may be more resistant to specificity effects (see, e.g., Schacter \& Church, 1992). Third, Graf and Ryan (1990) showed that font-specific effects in visual word priming emerged only after prior encoding that focused participants' attention on the physical characteristics of the words, but not after prior encoding that required participants to process the meaning of the words. In a similar way, encoding tasks that explicitly direct participants' attention to the acoustics of the environmental sounds, rather than to the verbal label of the sounds, may be necessary to reveal specificity effects. Fourth and perhaps more important, Stuart and Jones (1995) presented no data concerning how perceptually different the sound exemplars were from one another, nor did they show that their manipulation of exemplar match/mismatch affected any other measures of perception or memory. It is possible that the two exemplar sounds in each pair are functionally indistinguishable, especially when presented at very low levels.

The present study was carried out with these considerations in mind. The questions of interest were whether environmental sound priming is exemplar specific and whether such specificity depends on the nature of prior encoding (semantic vs. nonsemantic). Two different priming tests - that is, sound stem identification and sound identification in noise (SIIN) - were used. The different exemplars were pretested to ensure they were well discriminated. Explicit memory controls were also included for comparison purposes.

\section{GENERAL METHOD}

\section{Materials}

Target materials consisted of matched pairs of environmental sounds drawn from a variety of sound effect compact discs. For every target sound type, two sufficiently different sounds were available that would elicit the same name. Sounds within a pair were drawn from separate recording tracks. All of the sounds were recordings of real life events (e.g., toilet flushing, ping-pong game, typewriter, etc.). No animal sounds were included in this set. A number of human sounds (i.e., sneezing, snoring, kissing, and belching) and musical sounds (i.e., piano and harp) served as practice and filler items but were never included in the results or the statistical analyses. Each sound was digitized into the Apple Macintosh Centris 610 computer by SoundEdit software with the MacRecorder, at a sampling rate of $22 \mathrm{kHz}$ with 8-bit resolution. A 5-sec sound segment relatively free of long pauses and background noise was extracted from each sound. The first second of each 5-sec sound served as the sound stem. To form the cues for the SIIN test, a 5-sec white noise segment was generated and mixed with the 5-sec environmental sound in SoundEdit. The level of the noise mask was adjusted for each environmental sound so that mean identifiability would be above floor and below ceiling for most participants (see Experiment 3 for details).

The conditions under which auditory materials were presented were kept constant for all pilot testing and for all experiments reported in this article. Sounds were presented in a sound-attenuated 
room at a comfortable level through a single speaker (Sony Model SRS-38) approximately $50 \mathrm{~cm}$ from the participant's head and connected to the Centris 610 computer. The amplitude of each 5-sec environmental sound was individually adjusted in SoundEdit so that the perceived loudness was roughly the same as that of a standard (long duration 1000-Hz tone) across all stimuli. The root-mean square (RMS) and peak level of the standard were measured to be $71.0 \mathrm{~dB}$ SPL and $74.3 \mathrm{~dB}$ SPL (i.e., the average of 10 independent measurements of a 5-sec standard) with a precision-integrating sound level meter (Model NL-1 1, Rion Co. Ltd., Tokyo) at the approximate location of the participant's head. The RMS level, the peak level, and the crest factor (i.e., the ratio of peak to RMS) of each individual 5-sec sound were calibrated against this standard and are shown in Appendix A. In almost all cases, the individual amplitude adjustment amounted to normalizing the peak level of the stimulus to the peak level of the standard.

Separate identification and discrimination pilot studies were conducted to collect baseline information about the environmental sounds. Harvard undergraduate and graduate students served as participants in these pilot studies and received monetary compensation for their time. None of these participants participated in more than one pilot study, and none of them participated in any of the four experiments reported in this article. All the participants reported normal hearing.

Identification norms. Pilot studies were conducted to obtain norms for identifiability for the 5 -sec sounds presented in the clear. In these pilot studies, each listener was presented with environmental sounds (from 40 to 60 items across different pilot studies) one by one in different random orders. The listeners were given unlimited time to identify each sound and were asked to write down, in order of likelihood, the three responses that were most descriptive of each sound. (e.g., 1: footsteps, 2: hammering, 3: no response for the footstep sound.) Three examples were given to listeners before testing began. Most listeners provided just one response per stimulus. The most frequent first response for each sound was chosen as its name. The number of listeners who participated in each pilot study varied from 20 to 30 . Within each pilot study, only one exemplar from each sound category (e.g., footsteps, telephone ringing, etc.) was presented. The mean identifiability (i.e., percentage of name agreement) for these materials is shown in Appendixes A and B. No response was scored as incorrect. The same procedure was used to obtain identifiability data for the corresponding retrieval cues (i.e., $1-\mathrm{sec}$ stems in Experiments 1 and 2 and 5 -sec environmental sounds in white noise in Experiments 3 and 4; see each experiment for details). Each pilot experiment took roughly $30-45 \mathrm{~min}$.

Discrimination norms. To ensure that the participants could match the retrieval cues reliably to the corresponding study targets at minimal delay, naive listeners were tested in an AX matchmismatch judgment task. Ten new listeners were tested for each set of materials used in each of the four experiments. On every trial, the listeners heard two environmental sounds from the same category (e.g., footsteps), separated by $0.5 \mathrm{sec}$. The first sound was presented in the clear and was $5 \mathrm{sec}$ long (e.g., footstepsl). The second sound (i.e., the retrieval cue) was constructed either from the first sound (e.g., footsteps 1 , in stem or noise-masked form) or from a different exemplar (e.g., footsteps2) with equal probability. The participants were informed about the relation between the first and the second sound, and they were to determine whether the second sound matched or mismatched the first sound. The order of trial presentation was random. The listeners were given unlimited time for each trial and responded by pressing a key ("Y" or "N") on the keyboard. Listeners were shown three examples before they began. Testing generally lasted for $20-30 \mathrm{~min}$. The data were analyzed in terms of hit rate (e.g., a match response for sound 1 -soundl stem) and false alarm rate (e.g., a mismatch response for sound2-soundl stem) by item for Set 1 stems and Set 2 stems respectively.

\section{Procedure}

Many aspects of the method were constant across all four experiments in the present series. All the participants were tested individually in sound-attenuated testing rooms. Each experiment contained a critical encoding phase and a critical test phase. A number of noncritical filler tasks were added to the experiment to mask the relationship between the study phase and the test phase. The filler tasks were kept constant across experiments. The task order for all the experiments was the same: Filler Task $1 \rightarrow$ Encoding $\rightarrow$ Filler Task $2 \rightarrow$ Filler Task $3 \rightarrow$ Test $\rightarrow$ Filler Task 4 . This arrangement served to minimize the chance that the participants would choose to adopt explicit memory retrieval strategies in the nominally implicit conditions.

In Filler Task 1, the participants were given nonsense auditory patterns, and they learned to categorize them into eight categories with feedback. Filler Task 2 was identical to 1. In Filler Tasks 3 and 4 , the participants read different passages of text (e.g., "When txhe new compxutxer informaxxtxion txechnoloxgies were fxirst dexvelopxed, txhere wxas grxeaxt coxncxern that txhexse sxystexms ...") drawn from newspaper articles and differing from each other both in content and in the irrelevant distractor (in this case, $x$ ). The participants' task was to skip over the distractors and read the passage as fast as they could without making errors. The total duration of the retention interval (i.e., the time required for Filler Tasks 2 and 3 ) lasted from 15 to 20 min across all participants.

For the encoding phase of each experiment, half of the participants were given semantic encoding instructions. For each stimulus presented, these participants rated on a 3-point scale how frequently they encountered the type of sound described by the name in everyday life $(1$, rarely; 2 , sometimes; 3 , frequently). The other half of the participants were given nonsemantic encoding instructions. For each stimulus presented, these participants rated on a 3-point scale whether the pitch of the sound as a whole was lower than, roughly equal to, or higher than that of their own voice $(1$, lower; 2 , roughly equal; 3, higher). After exposure to each stimulus item, the participants responded by pressing the appropriate key on the keyboard. No mention of the later memory test was made at the time. No time limit for responding was imposed. The stimuli were 5 -sec environmental sounds presented with (Experiment 1) or without (Experiments 2,3, and 4) their corresponding names. The details of the test phase are presented in each experiment.

After the experiment was over, the participants received a questionnaire that assessed the extent to which they followed instructions. In particular, the participants in the perceptual priming group were queried as to whether they engaged in intentional explicit memory strategies in performing the priming task. Those participants who failed to follow instructions were replaced.

\section{EXPERIMENT 1}

There were two major purposes of Experiment 1: first, to test the hypothesis that perceptual priming of environmental sounds is exemplar specific, and second, to assess how such specificity depends on encoding and retrieval factors. At test, the participants were presented with stems of the target sounds and were asked to either identify them (sound stem identification) or explicitly recall the name of the studied sounds (sound stem cued recall). In both versions, some of the tested sounds were identical to the original sounds, some were different exemplar sounds that had the same names, and some were nonstudied sounds.

Sound stem identification was used here as the priming task for two reasons. First, a previous study on the per- 
ceptual priming of sounds (Chiu \& Schacter, 1995) used this task, and the results were consistent with other findings in the literature. Second, previous research suggests that when auditory stimuli are presented in a background of white noise, observation of specificity effects in perceptual priming may be less likely (e.g., Church, 1995; Schacter \& Church, 1992; but see Goldinger, 1996; Sheffert, 1998).

\section{Method}

Participants. Seventy-two Harvard undergraduate students participated in the experiment in exchange for a $\$ 10$ payment. All the participants identified themselves as native English speakers and reported normal hearing. The participants were randomly assigned to experimental conditions. Four participants in the stem identification group who were identified by questionnaire as using explicit recall strategies were replaced.

Materials, Design, and Procedure. In Experiment 1, 21 pairs of target sounds were used. One exemplar from each pair was randomly assigned to Set 1 , and the other to Set 2 . The mean identifiability for the $1-\sec$ sound stems was $.40(S D=.25)$ and $.36(S D=$ .19) for the sounds in Set 1 and Set 2, respectively. The mean identifiability for the $5-\mathrm{sec}$ sounds was $.80(S D=.16)$ and $.79(S D=.17)$ for Set 1 and Set 2, respectively. The difference in identifiability of sounds between sets was not statistically significant (all $t \mathrm{~s}<1$ ). Discrimination testing involved 84 trials ( 2 same trials and 2 different trials for each pair of sounds). The mean hit rate and false alarm rate were .97 and .06 for Set 1 stems and .90 and .04 for Set 2 stems. The mean $d^{\prime}$ 's were $2.92(S D=0.50)$ and $2.72(S D=0.62)$ for Set 1 and Set 2 , respectively, which were not significantly different from one another $\left[F(1,20)=2.04, M S_{e}=0.22\right]$. Mean identifiability and discriminability were thus matched across the two sets.

The design of Experiment 1 was $2 \times 2 \times 2 \times 3$ mixed factorial, with exemplar set at test ( 1 vs. 2 ), encoding (semantic vs. nonsemantic), and test (implicit vs. explicit) as between-subjects factors and stimulus form (same exemplar vs. different exemplar vs. nonstudied) as the within-subjects factor. The 21 sound pairs were randomly divided into three subsets of 7 each and were rotated across the three within-subjects conditions according to a Latin-square design. For instance, a participant receiving 21 stems in Set 2 form at test would have heard during encoding one subset of 7 in Set 1 form and one subset of 7 in Set 2 form. The last subset of 7 was not encoded. Targets thus appeared equally often in each experimental condition across participants.

The study list consisted of 14 critical targets randomly intermixed, preceded by two primacy fillers and followed by two recency fillers. Half of the critical items (i.e., 7) came from Set 1, the other from Set 2. On'each trial during the encoding phase, a sound name appeared on the computer screen for $2 \mathrm{sec}$, followed by the corresponding 5-sec environmental sound presented in the clear.

The participants were given a total of 32 trials at test. The first 4 were practice trials. A list of 28 items then followed, consisting of 21 critical items ( 7 same, 7 different, and 7 new) and another 7 filler sounds intermixed. Half of the participants received test stems from
Set 1 , the other half from Set 2 . The test list was presented in one predetermined random order for one half of the participants in each experimental condition, and in another for the other half of the participants. None of the filler items was included in any of the results or statistical analyses.

After the filled delay, half of the participants in each experiment were given a perceptual priming test, and half an explicit memory test. Those participants given the sound stem identification test were told that they would hear a series of brief sounds of $1 \mathrm{sec}$ each and that their task was to identify them. These participants were further informed that although some of the sound stems might be very similar to what they had heard earlier in the experiment, they should focus on the present task and always try to identify the sound stems by giving the very first response that came to mind. Those participants who were given the sound-stem-cued-recall test were told that they would hear a series of brief sounds of $1 \mathrm{sec}$ each and that their task was to use these brief sounds as cues to help them recall stimuli they encountered in the study phase. These participants were told that some of the sounds were identical to the ones they heard earlier, some sounds were of the same type but slightly different from what they heard before, and others were nonstudied sounds. The participants were instructed to respond only in the first two cases. It was emphasized that the participants should respond only if they were quite sure that they had encountered the stimulus event previously, and guessing was discouraged. Each participant was provided with a response sheet with numbered blanks for them to write down their responses. A press on the space bar initiated each trial. Then, a I-sec sound was immediately presented. The participants pressed the space bar once as soon as they were ready to respond (i.e., to record their reaction time) and then wrote down their response in the space provided on the response sheet.

\section{Results}

Following Bartlett (1977) and Ballas (1993), responses were scored as correct if the specified agent and action were synonymous with the designated name. For instance, sawing, person sawing wood, and sawing wood with a handsaw were all accepted as correct for the sound sawing wood. ${ }^{1}$ A .05 level of significance was adopted, unless otherwise stated.

Table 1 presents the mean proportion of correct responses as a function of stimulus form, encoding, and test. Preliminary analyses showed that none of the main and interaction effects involving exemplar set at test ( 1 vs. 2) and presentation order was significant, so the data were collapsed across these variables. Two questions were of primary interest. (1) Was there significant priming in various experimental conditions? (2) How was perceptual priming and explicit recall affected by encoding and stimulus form? Specifically, was perceptual priming and explicit recall dissociated as a function of encoding and/ or stimulus form?

Table 1

Mean Proportions (With Standard Errors) of Target Responses Produced as a Function of Encoding, Stimulus Form, and Test in Experiment 1

\begin{tabular}{|c|c|c|c|c|c|c|c|c|c|c|c|c|}
\hline \multirow[b]{4}{*}{ Test } & \multicolumn{12}{|c|}{ Encoding } \\
\hline & \multicolumn{6}{|c|}{ Nonsemantic } & \multicolumn{6}{|c|}{ Semantic } \\
\hline & \multicolumn{2}{|c|}{$\begin{array}{c}\text { Same } \\
\text { Exemplar }\end{array}$} & \multicolumn{2}{|c|}{$\begin{array}{l}\text { Different } \\
\text { Exemplar }\end{array}$} & \multicolumn{2}{|c|}{ Nonstudied } & \multicolumn{2}{|c|}{$\begin{array}{c}\text { Same } \\
\text { Exemplar }\end{array}$} & \multicolumn{2}{|c|}{$\begin{array}{l}\text { Different } \\
\text { Exemplar }\end{array}$} & \multicolumn{2}{|c|}{ Nonstudied } \\
\hline & $M$ & $S E$ & $M$ & $S E$ & $M$ & $S E$ & $M$ & $S E$ & $M$ & $S E$ & $M$ & $S E$ \\
\hline entificati & .65 & .04 & .56 & .05 & .41 & .04 & .73 & .0 & .56 & .05 & .37 & .05 \\
\hline Cued recall & .71 & .05 & .48 & .04 & .07 & .05 & .82 & .04 & .63 & .03 & .08 & .03 \\
\hline
\end{tabular}


Planned comparison between the studied condition and the nonstudied baseline showed that priming was significant in each of the experimental conditions $[t(51)=$ 3.91 and $2.48, M S_{\mathrm{e}}=0.033$, for the nonsemantic group, and $t(51)=5.36$ and $2.74, M S_{\mathrm{e}}=0.040$, for the semantic group)]. Priming score was calculated by subtracting baseline performance from the corresponding experimental conditions for each participant and entered into a 2 (semantic vs. nonsemantic) $\times 2$ (same exemplar vs. different exemplar) split-plot analysis of variance (ANOVA). The results showed that there was more priming in the same-exemplar than in the different-exemplar condition $\left[F(1,34)=6.79, M S_{\mathrm{e}}=0.045\right]$. Neither the main effect of encoding $\left[F(1,34)=1.17, M S_{\mathrm{e}}=0.087\right]$ nor the interaction effect $\left[F(1,34)=0.76, M S_{\mathrm{e}}=0.045\right]$ was significant. Similar analyses were performed for the explicit test data. The nonstudied baseline was subtracted from each corresponding experimental condition to yield an adjusted recall score. A similar $2 \times 2$ split-plot ANOVA revealed that cued recall in the same-exemplar condition was higher than that in the different-exemplar condition $\left[F(1,34)=25.4, M S_{\mathrm{e}}=0.033\right]$. Cued recall was also higher following semantic than following nonsemantic encoding $\left[F(1,34)=10.2, M S_{\mathrm{e}}=0.028\right]$. The interaction effect was not significant $\left[F(1,34)=0.14, M S_{\mathrm{e}}=\right.$ $0.033]$. Note that no interaction effect between test (priming vs. recall) and any of the other variables was significant in a $2 \times 2 \times 2$ combined ANOVA. ${ }^{2,3}$

\section{Discussion}

Experiment 1 revealed that semantic encoding benefited overall cued recall, relative to nonsemantic encoding. There was a similar trend toward higher levels of priming following semantic encoding, but analyses failed to confirm this in the individual $2 \times 2$ ANOVAs. There were more priming and cued recall in the same-exemplar condition than in the different-exemplar condition, and this exemplar specificity effect was independent of prior encoding operations.

Consider the priming results first. The finding that studying a different exemplar sound yields lower levels of priming than does studying the same exemplar is consistent with previous work in visual object priming (e.g., Biederman \& Cooper, 1991; Srinivas, 1993; Warren \& Morton, 1982) and auditory word priming (e.g., Church \& Schacter, 1994; Goldinger, 1996; Schacter \& Church, 1992; Sheffert, 1998; but see Luce \& Lyons, 1998). Moreover, environmental sound priming exhibits exemplar specificity under both semantic and nonsemantic encoding, as in auditory word priming (Church \& Schacter, 1994; Schacter \& Church, 1992).

With respect to the data on stem-cued recall, previous studies on recall or recognition memory have reported adverse effects of changes in stimulus features on explicit memory (e.g., Craik \& Kirsner, 1974; Goldinger, 1996; Goldinger, Pisoni, \& Logan, 1991; Palmeri et al., 1993; Sheffert \& Fowler, 1995; Srinivas, 1995), but a few other studies have not found such an effect (e.g., Church, 1995; Church \& Schacter, 1994; Schacter \& Church, 1992). Such specificity effects in explicit memory are sensitive to encoding and other factors (e.g., Curran et al., 1996; Goldinger, 1996; Graf \& Ryan, 1990) and may show up on reaction time as well as accuracy measures (e.g., Luce \& Lyons, 1998). In the present experiment, the participants might have remembered some semantic details about the exemplars, which might then have led to the specificity effect. This "connotative" hypothesis assumes that the specificity effect in cued recall is conceptual in nature. As such, it does not clearly explain why semantic encoding did not lead to a larger specificity effect than did nonsemantic encoding. The other possibility is that the retrieval cues of the present experiment provided mainly perceptual, rather than conceptual, information about the target and thus made it more likely for the participants to rely on data-driven processes to recover the remembered information (e.g., Graf \& Ryan, 1990; Roediger \& Blaxton, 1987).

At any rate, the observed exemplar specificity effect in priming is in direct contrast to Stuart and Jones's (1995) results. Before any strong conclusion is drawn, it should be noted that there were a number of procedural differences between Experiment 1 and Stuart and Jones's (1995) experiment. For instance, sound names were explicitly presented in Experiment 1, whereas Stuart and Jones's (1995) participants counted the number of syllables in the word that named the sound. It is possible that explicit presentation of the sound names may have created contextdependent encoding of the environmental sounds that favored specificity effects. Experiment 2 attempted to replicate Experiment 1 without presenting the sound names to the participants.

\section{EXPERIMENT 2}

\section{Method}

Participants. Seventy-two Harvard summer school and undergraduate students participated in the experiment in exchange for a $\$ 10$ payment. The participants were randomly assigned to experimental conditions. Seven participants in the stem identification group reported that they engaged in explicit memory retrieval during testing and were subsequently replaced.

Materials, Design, and Procedure. There were two differences between Experiments $I$ and 2. First, all the stimuli were now presented as environmental sounds at study, in the absence of visual presentation of the sound names. Second, 27 pairs of stimulus sounds were used in Experiment 2, instead of 21. These stimulus sounds consisted mostly of sounds used in Experiment 1 , with a few sound pairs being replaced because of lower identifiability and/or discriminability (see Appendix A for statistics of individual sounds). In this new set of sounds, mean identifiability of the 5 -sec sounds presented in quiet was .85 for Set $1(S D=.13)$ and .82 for $\operatorname{Set} 2(S D=$ .18). The corresponding identifiability for the 1-sec stems was .48 $(S D=.22)$ for Set 1 and $.46(S D=.18)$ for Set 2 . The two sets were well matched in identifiability $(t s<1)$. A pilot study employing a match-mismatch task, as in Experiment 1, used 108 trials ( 2 same and 2 different trials for each of 27 pairs of sounds) for each participant. The hit and false alarm rates were .93 and .05 for Set 1 stems 
and .87 and .04 for Set 2 stems. The corresponding $d$ 's were 2.79 $(S D=0.60)$ and $2.62(S D=0.81)$ for Set $I$ and Set 2 , respectively, which were not significantly different from one another $[F(1,26)=$ $\left.2.02, M S_{\mathrm{e}}=0.21\right]$.

Each trial in the study phase consisted of a presentation of the 5sec environmental sound, immediately followed by the 3-point scale appropriate to the particular encoding condition. Items from the same-exemplar and different-exemplar conditions were randomly intermixed to form the critical 18-item study list, buffered by 2 primacy and 2 recency filler items to form a 22-item study list. The test list consisted of 40 items. The first 4 trials were practice, and the remaining 36 consisted of 27 critical targets ( 9 same, 9 different, and 9 nonstudied) and 9 filler sounds intermixed in two different random orders. Across participants, items appeared equally often in every experimental condition. Other details of the procedure were the same as those in Experiment 1.

\section{Results}

Preliminary analyses showed that none of the effects involving exemplar set at test or presentation order was significant, so the data were collapsed across these variables. Table 2 presents the mean proportion of correct responses as a function of stimulus form, encoding, and test.

The set of statistical analyses performed was the same as that in Experiment 1. A planned comparison showed that priming was significant in each of the experimental conditions $\left[t(51)=4.15\right.$ and $2.49, M S_{\mathrm{e}}=0.018$, for the nonsemantic group; $t(51)=3.50$ and $2.05, M S_{\mathrm{e}}=0.024$, for the semantic group]. A $2 \times 2$ mixed ANOVA on the priming scores revealed a significant main effect of stimulus form $\left[F(1,34)=8.77, M S_{\mathrm{e}}=0.011\right]$, but the main effect of encoding $\left[F(1,34)=0.01, M S_{\mathrm{e}}=0.075\right]$ and the interaction effect $\left[F(1,34)=0, M S_{\mathrm{e}}=0.011\right]$ were not significant. A similar analysis performed on the adjusted cued-recall data showed that the main effect of stimulus form $\left[F(1,34)=9.59, M S_{\mathrm{e}}=0.014\right]$ and that of encoding $\left[F(1,34)=24.4, M S_{\mathrm{e}}=0.032\right]$ were significant but their interaction effect was not $\left[F(1,34)=0.44, M S_{\mathrm{e}}=0.014\right]$. Overall, changing the exemplar from study to test reduced both priming and cued recall, and such a specificity effect was independent of encoding. Semantic encoding improved cued recall over nonsemantic encoding, but encoding had no effect on sound priming. ${ }^{4}$

\section{Discussion}

The results of Experiments 1 and 2 differ in two respects. The levels of priming and cued recall appear to be higher in Experiment 1 than in Experiment 2. In particular, performance for the same-exemplar condition, but not for the different-exemplar condition, seems to be higher overall in Experiment 2 than in Experiment 1. These impressions were borne out by an exploratory $2 \times 2 \times 2 \times 2$ ANOVA, treating experiment (1 vs. 2) as an extra betweensubjects factor, given that the number of participants per condition and the design were identical in the two experiments. The main effect of experiment $[F(1,136)=$ $\left.22.0, M S_{\mathrm{e}}=0.06\right]$ and the two-way interaction between stimulus form and experiment $\left[F(1,136)=5.05, M S_{\mathrm{e}}=\right.$ $0.03]$ were significant. No other interaction effect involving experiment was significant (all $F_{\mathrm{S}}<2.4$, all $p \mathrm{~s}>.12$ ).

Such results should be interpreted with caution, given that they rely on analyses across experiments. Even if name presentation were, indeed, solely responsible for the difference between experiments, it remains an open question what the exact mechanism involved is and whether it is qualitatively the same for priming and for recall. One possibility is that name presentation directs participants' attention to certain perceptual details of the target sounds, which enhances both subsequent recall and priming in a way that does not depend on the particular encoding operations. This is similar to the process of intraitem integration (e.g., Graf \& Ryan, 1990). Note that name presentation alone does not prime environmental sound identification (see, e.g., Chiu \& Schacter, 1995; Stuart \& Jones, 1995, 1996).

At any rate, Experiment 2 showed that priming and cued recall were both exemplar specific and that such specificity was independent of encoding. Encoding had a strong effect on cued recall but did not affect priming. Importantly, priming remains exemplar specific in the absence of explicit sound name presentation. These results replicate qualitatively those of Experiment 1 and are inconsistent with Stuart and Jones's (1995) finding.

\section{EXPERIMENT 3}

In light of the findings of Experiments 1 and 2, it is puzzling that Stuart and Jones (1995) did not find exemplarspecific priming. In their procedure, studied and nonstudied sounds were first presented at a loudness level close to the detection threshold. Level was then increased in constant stepsizes until participants succeeded in identification. This method ensures that target sounds are always heard at low loudness levels and are more likely to be dominated by physiological noise, a condition that may not be favorable for specificity effect in auditory

Table 2

Mean Proportions (With Standard Errors) of Target Responses Produced as a Function of Encoding, Stimulus Form, and Test in Experiment 2 Encoding

\begin{tabular}{|c|c|c|c|c|c|c|c|c|c|c|c|c|}
\hline \multirow[b]{4}{*}{ Test } & \multicolumn{12}{|c|}{ Encoding } \\
\hline & \multicolumn{6}{|c|}{ Nonsemantic } & \multicolumn{6}{|c|}{ Semantic } \\
\hline & \multicolumn{2}{|c|}{$\begin{array}{c}\text { Same } \\
\text { Exemplar }\end{array}$} & \multicolumn{2}{|c|}{$\begin{array}{l}\text { Different } \\
\text { Exemplar }\end{array}$} & \multicolumn{2}{|c|}{ Nonstudied } & \multicolumn{2}{|c|}{$\begin{array}{c}\text { Same } \\
\text { Exemplar }\end{array}$} & \multicolumn{2}{|c|}{$\begin{array}{l}\text { Different } \\
\text { Exemplar }\end{array}$} & \multicolumn{2}{|c|}{ Nonstudied } \\
\hline & $M$ & $S E$ & $M$ & $S E$ & $M$ & $S E$ & $M$ & $S E$ & $M$ & $S E$ & $M$ & $S E$ \\
\hline Identification & .62 & .03 & .55 & .03 & .44 & .03 & .64 & .05 & .57 & .05 & .46 & .05 \\
\hline Cued recall & .53 & .03 & .43 & .04 & .09 & .02 & .67 & .03 & .60 & .03 & .04 & .02 \\
\hline
\end{tabular}


priming to emerge (e.g., Schacter \& Church, 1992). Experiment 3 was a conceptual replication of Stuart and Jones's (1995) experiment with a priming test in which target sounds were presented together with an explicit white noise masker. The targets were presented once, rather than in incremental steps of loudness, to discourage guessing using explicit memory strategies. This paradigm is more similar procedurally to those used for word identification in previous research. For comparison, the yes/no sound recognition test was used as another explicit memory measure. As in Experiment 1, both semantic and nonsemantic encoding conditions were included.

\section{Method}

Participants. Seventy-two Harvard undergraduate students participated in the experiment in exchange for a $\$ 10$ payment. The participants were randomly assigned to experimental conditions. Six participants in the SIIN group reported that they engaged in explicit memory retrieval during testing and were subsequently replaced.

Materials, Design, and Procedure. The design was a $2 \times 2 \times$ $2 \times 3$ mixed factorial, with exemplar set at test ( 1 vs. 2 ), encoding (nonsemantic vs. semantic), and test (SIIN vs. recognition) as between-subjects factors and stimulus form (same exemplar vs. different exemplar vs. nonstudied) as the within-subjects factor. Experiment 3 was similar to Experiment 2, except that the SIIN task and a recognition memory task were used in the test phase.

The set of critical sounds in Experiment 3 was identical to that used in Experiment 2. The list of test items for the SIIN test consisted of 5-sec environmental sounds mixed with white noise. The amplitude of the white noise and, hence, the signal-to-noise ratio for each test item were pretested in a pilot study so that identifiability would be below ceiling and above floor (see Appendix B for statistics on individual SIIN cues). This pilot study was carried out in the same manner as the other, except that only 12 participants were used. Identifiability for the SIIN cues did not differ for Set 1 $($ mean $=.22, S D=.30)$ and Set $2($ mean $=.24, S D=.25 ;$ all $t \mathrm{~s}<1)$ Discrimination testing involving 10 naive participants used a total of 108 trials ( 2 same trials and 2 different trials for each of the 27 pairs). The corresponding $d^{\prime}$ 's were $2.24(S D=0.85)$ and 2.21 $(S D=0.96)$ for Set 1 and Set 2, respectively, which were not significantly different from one another $\left[F(1,26)<1, M S_{\mathrm{e}}=0.88\right]$.

In the SIIN task, the participants were instructed that they were to identify the environmental sound with the first response that came to mind or write "White Noise" if they failed to detect any sound in the white noise. A keypress initiated the presentation of the 5 -sec test item on each trial, and the participants wrote down their responses on an answer sheet. The participants were given a total of 44 trials. The first four were practice trials, in which the participants listened to a white noise sound, a pure tone embedded in white noise, and two environmental sounds presented in white noise (i.e., laughing and screaming). The target list of 40 items then followed, consisting of 27 critical items ( 18 studied, 9 nonstudied), nine filler sounds, and four white noise sounds randomly intermixed. The target list was presented in one of four predetermined random orders for the participants in each experimental condition. None of the responses to the filler or the white noise only items was included in the analyses. All responses of "White Noise" were scored as incorrect

The list of test items for the recognition test consisted of the 1sec sound stems used in Experiment 2. Sound stems were used instead of the full $5 \mathrm{sec}$ of the environmental sounds to avoid ceiling effects. The participants were instructed to listen to a series of sounds and press one of three different keys (i.e., $1=$ same, $2=$ different, $3=n e w)$ to indicate whether they have hc ard the same exemplar or a different exemplar before, in the study phase, or whether the sound was a new item. The difference between the same- and the differentexemplar conditions was illustrated with examples. The test was self-paced. The test list was the same as that used in Experiment 2 and began with 4 practice items, followed by a 36 -item list that consisted of 27 critical targets and nine filler sound stems intermixed in two different random orders.

\section{Results}

Table 3 presents the mean proportion of correct responses as a function of stimulus form and encoding on the SIIN test. Table 4 presents the hit rate and false alarm rate on the recognition test as a function of stimulus form and encoding. All responses of 1: same or 2: different were treated as old, and those of 3: new were treated as new. This is in keeping with previous research on recognition memory of words and pictures, where participants were simply required to indicate whether a target item was presented, regardless of its perceptual form. Preliminary analyses showed that none of the interaction effects involving exemplar set at test (1 vs. 2) and presentation orders was significant, so the data were collapsed across these variables in all cases. The statistical analyses carried out were similar to those in the previous experiments.

Planned comparisons showed that for participants in the nonsemantic encoding group, priming was significant in both the same-exemplar condition $[t(51)=3.13]$ and the different-exemplar condition $\left[t(51)=2.14, M S_{\mathrm{e}}=\right.$ $0.016]$. For the semantic group, priming was not significant in both the same-exemplar condition $[t(51)=1.51]$ and the different-exemplar condition $[t(51)=1.26$, $M S_{\mathrm{e}}=0.017 \mathrm{j}$. The results should be interpreted with caution because of the substantial numerical difference in baseline for the two groups (.26 vs. .20), although such difference did not reach statistical significance $(t<1.36)$.

Table 3

Mean Proportions (With Standard Errors) of Target Responses Produced on the SIIN Task as a Function of Encoding and Stimulus Form in Experiment 3

\begin{tabular}{|c|c|c|c|c|c|c|}
\hline \multirow[b]{3}{*}{ Encoding } & \multicolumn{6}{|c|}{ Stimulus Form } \\
\hline & \multicolumn{2}{|c|}{$\begin{array}{c}\text { Same } \\
\text { Exemplar }\end{array}$} & \multicolumn{2}{|c|}{$\begin{array}{l}\text { Different } \\
\text { Exemplar }\end{array}$} & \multicolumn{2}{|c|}{ Nonstudied } \\
\hline & $M$ & $S E$ & $M$ & $\overline{S E}$ & $M$ & $S E$ \\
\hline Nonsemantic & .34 & .03 & .30 & .03 & .20 & .02 \\
\hline Semantic & .34 & .04 & .33 & .04 & .26 & .04 \\
\hline
\end{tabular}

Table 4

Hit and False Alarm Rates (With Standard Errors) on the Recognition Memory Task as a Function of Encoding and Stimulus Form in Experiment 3

\begin{tabular}{|c|c|c|c|c|c|c|}
\hline \multirow[b]{3}{*}{ Encoding } & \multicolumn{6}{|c|}{ Stimulus Form } \\
\hline & \multicolumn{2}{|c|}{$\begin{array}{c}\text { Same } \\
\text { Exemplar }\end{array}$} & \multicolumn{2}{|c|}{$\begin{array}{l}\text { Different } \\
\text { Exemplar }\end{array}$} & \multicolumn{2}{|c|}{ Nonstudied } \\
\hline & $M$ & $S E$ & $M$ & $S E$ & $M$ & $S E$ \\
\hline Nonsemantic & .83 & .03 & .65 & .05 & .33 & .04 \\
\hline Semantic & .88 & .06 & .80 & .03 & .28 & .03 \\
\hline
\end{tabular}

Note-Numbers indicate the proportion of times the participants responded same or different (i.e., old) to the stimulus. 
A $2 \times 2$ mixed ANOVA performed on the priming score revealed no significant effects [all $F \mathrm{~s}(1,34)<1.2, M S_{\mathrm{e}}=$ 0.012 within-subjects and $M S_{\mathrm{e}}=0.058$ between-subjects]. Thus, priming was not reliably different across experimental conditions.

Analyses were also conducted for the recognition memory data. The false alarm rate was subtracted from the hit rate for each corresponding experimental condition to yield an adjusted recognition score, which was entered into a $2 \times 2$ split-plot ANOVA. The participants recognized more items in the same-exemplar condition than in the different-exemplar condition $\left[F(1,34)=15.1, M S_{\mathrm{e}}=\right.$ $0.020]$. The participants also recognized more items following semantic encoding than following nonsemantic encoding $\left[F(1,34)=6.06, M S_{\mathrm{e}}=0.065\right]$. The interaction between encoding and stimulus form was not significant $\left[F(1,34)=2.20, M S_{\mathrm{e}}=0.020\right] .{ }^{5}$

Although not the focus of the present article, Experiment 3 also yielded data concerning the extent to which participants were biased to call a recognized item same in recognition memory. Table 5 presents the mean conditional probability of items being called same, given that they were identified as being old (i.e., given a same or a different response). Neither the main effect of encoding nor its interaction with stimulus form was significant (both $F \mathrm{~s}<1.1$ ). The effect of stimulus form was highly significant $\left[F(2,68)=16.2, M S_{\mathrm{e}}=0.018\right]$ : The conditional probability of a same response in the sameexemplar condition was higher than that in the differentexemplar condition, which was in turn higher than that in the nonstudied condition (both $t \mathrm{~s}>4.0$ ). That is, the participants were less likely to call items in the differentexemplar condition different (i.e., .45), conditionalized on an old response, than in the nonstudied condition (i.e., $.61)$, revealing a response bias. This difference, however, is smaller than the difference in conditional probability of a same response between the same-exemplar condition (i.e., .80) and the nonstudied condition (.38).

It is unclear whether the sameldifferent judgment can be attributable entirely to a same bias based on overall memory strength. For example, overall hit rates in the same-exemplar/nonsemantic condition $(.83)$ and the different-exemplar/semantic condition (.80) were matched, and yet the conditional probability of same responses $(.80)$ was much higher in the former than in the latter (.52). This result suggests the explicit retention of perceptual

Table 5

Mean Proportions (With Standard Errors) of Same Response in the Recognition Memory Task Conditionalized on an Old Response (i.e., Same or Different) as a Function of Encoding and Stimulus Form in Experiment 3

\begin{tabular}{|c|c|c|c|c|c|c|}
\hline \multirow[b]{3}{*}{ Encoding } & \multicolumn{6}{|c|}{ Stimulus Form } \\
\hline & \multicolumn{2}{|c|}{$\begin{array}{c}\text { Same } \\
\text { Exemplar }\end{array}$} & \multicolumn{2}{|c|}{$\begin{array}{l}\text { Different } \\
\text { Exemplar }\end{array}$} & \multicolumn{2}{|c|}{ Nonstudied } \\
\hline & $M$ & $S E$ & $\bar{M}$ & $\overline{S E}$ & $M$ & $\overline{S E}$ \\
\hline Nonsemantic & .80 & .03 & .55 & .05 & .39 & .04 \\
\hline Semantic & .80 & .05 & .52 & .04 & .36 & .02 \\
\hline
\end{tabular}

details about the input stimulus form. It is perhaps more plausible that an omnibus same bias operates in conjunction with explicit memory for perceptual details, thus reducing accuracy for same/different judgments in the different-exemplar condition. Further investigation in the future is required to resolve this issue.

\section{Discussion}

In contrast to Experiments 1 and 2, there was no evidence of exemplar-specific priming in Experiment 3. This result is consistent with previous reports of auditory word priming's being less sensitive to changes in voice or speaking rate when the priming task requires identification in white noise. However, note that the SIIN cues in Experiment 3 were also less discriminable within a pair than were the corresponding stem cues. Test cues within a pair were much less discriminable (i.e., lower $d^{\prime}$ ) in Experiment 3 $\left(d^{\prime}=2.24\right.$ and 2.21 for Sets 1 and 2) than in Experiment 1 $\left[d^{\prime} \mathrm{s}=2.92\right.$ and $\left.2.72 ; F(1,52)=13.56, M S_{\mathrm{e}}=0.609\right]$ and Experiment $2\left[d^{\prime} \mathrm{s}=2.79\right.$ and $2.62 ; F(1,52)=7.83$, $\left.M S_{\mathrm{e}}=0.789\right]$. Note also that the level of baseline performance was lower in Experiment 3, as compared with the previous experiments (both $t \mathrm{~s}>15.0, M S_{\mathrm{e}}<0.024$ ). Given these differences, a new set of SIIN cues whose discriminability and identifiability were better matched to those of the stem cues was constructed and used in Experiment 4 . Because that experiment focused on the results of the SIIN test, no explicit memory condition was included.

Regarding recognition memory, the present results are consistent with others in the literature showing that exemplar-specific information does influence recognition memory (e.g., Goldinger, 1996; Luce \& Lyons, 1998; Palmeri et al., 1993; Sheffert \& Fowler, 1995). This data pattern is identical to those of explicit stem recall in the previous experiments.

\section{EXPERIMENT 4}

\section{Method}

Participants. Thirty-six Harvard undergraduate students participated in the experiment in exchange for a $\$ 10$ payment. The participants were randomly assigned to experimental conditions. Eight participants reported that they engaged in explicit memory retrieval during testing and were subsequently replaced.

Materials, Design, and Procedure. Experiment 4 differed from Experiment 3 in two respects. First, no explicit memory condition was included in this experiment. Second, a set of new SIIN sound cues was constructed as follows. First, the SIIN cues used in Experiment 3 that were not well discriminated $\left(d^{\prime}<2.5\right)$ by the participants were identified. The amplitude levels of the white noise masker associated with each of these individual SIIN cues was decreased by $90 \%$ (roughly a change of $-1 \mathrm{~dB}$ ), and the attenuated masker was remixed with the target sound. Three pairs of SIIN cues were still not discriminated well and were eventually replaced by three new pairs. The entire set of SIIN cues was then pretested for discrimination, as before. For the new set, $d$ 's were 2.60 and 2.52 for Sets 1 and 2, respectively, and were not significantly different from those of Experiment $1\left[F(1,46)=3.34, M S_{\mathrm{e}}=0.46, p=.07\right]$ and Experiment 2 $\left[F(1,52)=0.82, M S_{\mathrm{e}}=0.65\right]$. The mean identifiability for the 5 -sec sounds was $86.3 \%(S D=13.9 \%)$ for Set 1 and $87.9 \%(S D=12.2 \%)$ for Set 2 . The difference in identifiability of sounds between sets was 
not significant statistically $(t<1)$. No pilot study was conducted to collect identification norms for the new SIIN cues, owing to the substantial overlap of materials from Experiment 3. Individual statistics regarding the SIIN cues are presented in Appendix B.

\section{Results and Discussion}

Preliminary analyses showed that the main effect of exemplar set at test ( 1 vs. 2) approached significance $\left[F(1,32)=3.71, M S_{\mathrm{e}}=0.022, p=.062\right]$. However, none of the interaction effects involving this factor was statistically significant (all $F \mathbf{s}<1.47$ ). No effect involving presentation order was significant. The data were thus collapsed across these two variables.

Table 6 presents the mean proportion of correct responses as a function of stimulus form and encoding. Note that baseline performance in Experiment 4 was not significantly different from those in Experiments 1 or 2 (both $t \mathrm{~s}<$ 1.7). Planned comparisons showed that priming was significant in three of the four conditions $\left[t(51) \mathrm{s}>2.55, M S_{\mathrm{e}}=\right.$ 0.012 for the semantic and 0.014 for the nonsemantic group]. Only the different-exemplar nonsemantic condition failed to show significant priming $[t(51)=0.786]$. Priming scores were also calculated and entered into a $2 \times 2$ mixed ANOVA. The analysis revealed that changing exemplars between study and test reduced priming $[F(1,34)=5.02$, $\left.M S_{\mathrm{e}}=0.011\right]$, but the main effect of encoding $[F(1,34)=$ .28, $\left.M S_{\mathrm{e}}=0.039\right]$ and the interaction effect $[F(1,34)=$ $\left.2.23, M S_{\mathrm{e}}=0.011\right]$ were not significant.

The results of Experiment 4 are clear. Priming could be exemplar specific if the SIIN cues were matched in discriminability and identifiability to the sound stem cues used in Experiments 1 and 2. Note that the SIIN cues were discriminable in Experiment 3, where the $d$ 's were in a respectable range of 2.1 . The results from Experiments 3 and 4 together suggest that subtle differences in cue discriminability may lead to different patterns of specificity in priming: Cues that are more perceptually discriminable are more likely to give rise to specific priming (see, e.g., Goldinger, 1996). Consistent with recent findings (Goldinger, 1996; Sheffert, 1998), the data here argue against the idea that auditory priming will not show specificity effects when the test requires identification in white noise.

\section{GENERAL DISCUSSION}

The main findings of the present series of experiments can be summarized as follows. Exemplar changes be- tween study and test, regardless of encoding operations, reduced both environmental sound priming and cued recall. This specificity effect was unaffected by encoding manipulations and was present in both the stem-cued task and the SIIN task. In general, semantic encoding improved cued recall relative to nonsemantic encoding, but this variable had little effect on priming. Overall performance in the same-exemplar condition, for priming as well as for recall, was reduced in the absence of name presentation at encoding. However, exemplar-specific priming emerged even in the absence of name presentation. Priming was found to be specific as long as the exemplars within a pair were highly discriminable. The major features of each experiment are summarized in Table 7.

The specific component of priming (i.e., same-different) throughout the four experiments was modest in numerical terms but robust; it accounted consistently for $33 \%-$ $50 \%$ of the entire repetition priming effect. The present results argue against the idea that perceptual priming for environmental sounds is mediated by purely abstract representations, such as audiogens. The data from the present experiments, together with previous findings (Chiu \& Schacter, 1995; Stuart \& Jones, 1995, 1996), present a picture of environmental sound priming that is similar to that of auditory word priming, which is sensitive to physical features of the stimuli and little affected by encoding operations. Note that in the present experiments, priming did not show a depth of encoding effect, suggesting minimal contamination from explicit memory. Note also that the specificity effects in priming show sensitivity to name presentation. At any rate, there is no evidence to show that sound priming is nonspecific and any different from priming in other stimulus domains.

Although there have been numerous reports of perceptual specificity in priming in the literature, several recent studies have demonstrated absence of perceptual specificity. It has been suggested that the absence of voice specificity effects in word identification tasks with white noise maskers implies that auditory word priming depends on access to a right-hemisphere-based memory subsystem that is particularly sensitive to masking by white noise (e.g., Church, 1995; Schacter \& Church, 1992). Similarly, findings of absence of form-specific priming effects in amnesic patients (e.g., Kinoshita \& Wayland, 1993; Schacter, Church, \& Bolton, 1995; but see Vaidya, Gabrieli, Verfaellie, Fleischman, \& Askari, 1998) and elderly participants (e.g., Schacter, Church, \& Osowiecki, 1994) have been taken as strong evidence that

Table 6

Mean Proportions (With Standard Errors) of Target Responses Produced on the SIIN Task as a Function of Encoding and Stimulus Form in Experiment 4

\begin{tabular}{|c|c|c|c|c|c|c|c|c|c|c|c|c|}
\hline \multirow[b]{4}{*}{ Stimulus Form } & \multicolumn{12}{|c|}{ Encoding } \\
\hline & \multicolumn{6}{|c|}{ Nonsemantic } & \multicolumn{6}{|c|}{ Semantic } \\
\hline & \multicolumn{2}{|c|}{$\begin{array}{c}\text { Same } \\
\text { Exemplar }\end{array}$} & \multicolumn{2}{|c|}{$\begin{array}{l}\text { Different } \\
\text { Exemplar }\end{array}$} & \multicolumn{2}{|c|}{ Nonstudied } & \multicolumn{2}{|c|}{$\begin{array}{c}\text { Same } \\
\text { Exemplar }\end{array}$} & \multicolumn{2}{|c|}{$\begin{array}{l}\text { Different } \\
\text { Exemplar }\end{array}$} & \multicolumn{2}{|c|}{ Nonstudie } \\
\hline & $M$ & $S E$ & $M$ & $S E$ & $M$ & $S E$ & $M$ & $S E$ & $M$ & $S E$ & $M$ & $S E$ \\
\hline Identification & .44 & .03 & .35 & .02 & .32 & .03 & .41 & .03 & .40 & .04 & .30 & .02 \\
\hline
\end{tabular}


Table 7

Summary of Major Features of Experiments 1, 2, 3, and 4

\begin{tabular}{|c|c|c|c|c|c|}
\hline Experiment & $\begin{array}{l}\text { Sound Names } \\
\text { at Encoding? }\end{array}$ & $\begin{array}{l}\text { Priming } \\
\text { Test }\end{array}$ & $\begin{array}{c}\text { Discriminability } \\
\text { of the Two Sets of } \\
\text { Priming Test Cues }\left(d^{\prime}\right)\end{array}$ & $\begin{array}{l}\text { Specificity } \\
\text { Effects in } \\
\text { Priming? }\end{array}$ & $\begin{array}{c}\text { Explicit } \\
\text { Memory } \\
\text { Test }\end{array}$ \\
\hline 1 & yes & $\begin{array}{l}\text { Sound stem } \\
\text { identification }\end{array}$ & 2.92 and 2.72 & yes & $\begin{array}{l}\text { Stem-cued } \\
\text { recall }\end{array}$ \\
\hline 2 & no & $\begin{array}{l}\text { Sound stem } \\
\text { identification }\end{array}$ & 2.79 and 2.62 & yes & $\begin{array}{l}\text { Stem-cued } \\
\text { recall }\end{array}$ \\
\hline 3 & no & $\begin{array}{l}\text { Sound } \\
\text { identification } \\
\text { in noise (SIIN) }\end{array}$ & 2.24 and 2.21 & no & $\begin{array}{l}\text { Recognition } \\
\text { memory for } \\
\text { sound stems }\end{array}$ \\
\hline 4 & no & $\begin{array}{l}\text { Sound } \\
\text { identification } \\
\text { in noise (SIIN) }\end{array}$ & 2.60 and 2.52 & yes & \\
\hline
\end{tabular}

access to the representations that support form-specific priming may be impaired in these populations. In the case of environmental sounds, absence of form-specific priming is taken to reflect the abstract nature of the underlying representations (Stuart \& Jones, 1995).

The validity of all of the above arguments depends on a crucial assumption of cue discriminability and deserves further comment. This assumption requires not only that the targets in their alternative forms are discriminable in the absence of stimulus degradation. More important, the perceptually impoverished retrieval cues need to be discriminable and to match their corresponding targets better than do the rival cues. For instance, suppose stems of 1-msec duration are extracted from two highly distinguishable tokens of the word "window," one spoken by a male and the other by a female speaker. Further suppose that the stems differ substantially in peak level (e.g., one at 60 and one at $70 \mathrm{~dB}$ SPL). The stems would be perceived as clicks. Even though the stems may be well discriminated from one another in some incidental feature, such as level, they are functionally identical with respect to identification in that they do not facilitate access to those features that differentiate the individual tokens (e.g., voice of the speaker). In this case, even if the targets and the cues were well discriminated, it would still be trivial not to find token-specific priming. Similarly, two visual word stems may be less distinctive in upper- and lowercases than are the corresponding targets words (WOO vs. woo and WOODEN vs. wooden), and the fact that these stems do not lead to specific priming need not be theoretically relevant. In this vein, note that the results of Experiments 3 and 4 suggest that even subtle differences in cue discriminability could be sufficient to produce different patterns of form specificity effects. Careful control for cue discriminability is therefore indispensable not only in comparisons of form-specific priming across experimental conditions, but particularly in comparisons across subject populations in which differences in acuity or discrimination ability are expected. The magnitude of the specificity effect has been shown to correlate positively with the judged perceptual distance between the targets (e.g., Goldinger, 1996), so future studies should always provide some estimate of perceptual similarity for the stimuli.

Information specific to the sound exemplars also affected recall and recognition in Experiments 1-3. Although depth of encoding had an overall effect on recall and recognition, it did not affect the magnitude of the exemplar specificity effect. As a first approximation, it is tempting to conclude from this that the specificity effect in explicit memory is nonsemantic in nature. However, the effects of other encoding tasks that emphasized more or less semantic encoding need to be assessed before firm conclusions can be drawn. Consistent with other studies in the literature (e.g., Goldinger, 1996; Luce \& Lyons, 1998; Palmeri et al., 1993; Sheffert \& Fowler, 1995), the present study shows that explicit memory can be affected by surface feature manipulations. The issue of cue discriminability discussed earlier applies equally to explicit memory research, although most studies in the past did not use perceptually degraded targets as retrieval cues.

In summary, the present study dovetails with a growing body of literature in suggesting that auditory sound representations, like their word counterparts, preserve specific stimulus information in memory. The question of the grain of details of these representations is left to future experiments that use more subtle changes in the features of the stimulus sounds than exemplars. The data from the present study are broadly consistent with the transfer-appropriate processing principle and, hence, with both the perceptual representation system account and the processing account of priming (e.g., Schacter \& Buckner, 1998). On the basis of these data, it is tempting to speculate on the existence of a lexicon of sound recognition units, each presemantic in nature and preserving exemplar-specific features of each type of environmental sounds. These units can be activated by a recent encounter with a target sound and are functionally separable from those mediating spoken word recognition. Interestingly, a recent report in the literature described il rare case of a patient who had severe difficulty recognizing nonverbal sounds but who was normal on word comprehension, word repetition, memory, and auditory brainstem response (Habib et al., 1995). Alternatively, it is also possible that 
a memory system that stores each individual episode as a separate trace mediates priming, in which the fluency of reprocessing of a target sound depends on the overlap of common features between the target and other traces in memory (see, e.g., Goldinger, 1996; Graf \& Ryan, 1990).

\section{REFERENCES}

BaLlas, J. A. (1993). Common factors in the identification of an assortment of brief everyday sounds. Journal of Experimental Psychology. Human Perception \& Performance, 19, 250-267.

BARTLETT, J. C. (1977). Remembering environmental sounds: The role of verbalization at input. Memory \& Cognition, 5, 404-414.

Biederman, I., \& COOPER, E. E. (1991). Evidence for complete translational and reflectional invariance in visual object priming. Perception, 20, 585-593.

Biederman, I., \& CoOper, E. E. (1992). Size invariance in visual object priming. Journal of Experimental Psychology: Human Perception \& Performance, 18, 121-133.

Blaxton, T. A. (1989). Investigating dissociations among memory measures: Support for a transfer-appropriate processing framework. Journal of Experimental Psychology: Learning, Memory, \& Cognition, 15, 657-668

Carr, T. H., Brown, J. S., \& Charalambous, A. (1989). Repetition and reading: Perceptual encoding mechanisms are very abstract but not very interactive. Journal of Experimental Psychology: Learning. Memory, \& Cognition, 15, 763-778.

CAVE, C. B., Bost, P. R., \& CoBB, R. E. (1996). Effects of color and pattern on implicit and explicit picture memory. Journal of Experimental Psychology: Learning, Memory, \& Cognition, 22, 639-653.

CHIU, C.-Y. P., \& SChaCTER, D. L. (1995). Auditory priming for nonverbal information: Implicit and explicit memory for environmental sounds. Consciousness \& Cognition, 4, 440-458.

ChURCH, B. A. (1995). Perceptual specificity of auditory priming: Implicit memory for acoustic information. Unpublished doctoral dissertation, Harvard University.

Church, B. A., \& Schacter, D. L. (1994). Perceptual specificity of auditory priming: Implicit memory for voice intonation and fundamental frequency. Journal of Experimental Psychology: Learning, Memory, \& Cognition, 20, 521-533.

Cooper, L. A., Schacter, D. L., Ballesteros, S., \& Moore, C. (1992). Priming and recognition of transformed three-dimensional objects: Effects of size and reflection. Journal of Experimental Psychology: Learning, Memory, \& Cognition, 18, 43-57.

Craik, F. I. M., \& Kirsner, K. (1974). The effect of speaker's voice on word recognition. Quarterly Journal of Experimental Psychology, 26, 274-284.

Curran, T., Schacter, D. L., \& Bessenoff, G. (1996). Visual specificity effects on word stem completion: Beyond transfer appropriate processing? Canadian Journal of Experimental Psychology, 50, 22-33.

GOLDINGER, S. D. (1996). Words and voices: Episodic traces in spoken word identification and recognition memory. Journal of Experimental Psychology: Learning. Memory, \& Cognition, 22, $1166-1183$.

Goldinger, S. D., Pisoni, D. B., \& Logan, J. S. (1991). On the nature of talker variability effects on serial recall of spoken word lists. Journal of Experimental Psychology: Learning, Memory, \& Cognition, 17, $152-162$.

Graf, P., \& Ryan, L. (1990). Transfer-appropriate processing for implicit and explicit memory. Journal of Experimental Psychology: Learning, Memory, \& Cognition, 16, 978-992.

Habib, M., Daquin, G., Milandre, L., Royere, M. L., Rey, M., Lanteri, A., Salamon, G., \& Khalil, R. (1995). Mutism and auditory agnosia due to bilateral insular damage: Role of the insula in human communication. Neuropsychologia, 33, 327-339.

JACKSON, A., \& MORTON, J. (1984). Facilitation of auditory word recognition. Memory \& Cognition, 12, 568-574.

KINOSHITA, S., \& WAYLAND, S. V. (1993). Effects of surface features on word-fragment completion in amnesic participants. American Journal of Psychology, 106, 67-80.

KoIvisto, M. (1995). On functional brain asymmetries in perceptual priming. Brain \& Cognition, 29, 36-53.
LUCE, P. A., \& LYONS, E. A. (1998). Specificity of memory representations for spoken words. Memory \& Cognition, 26, 708-715.

Marsolek, C. J., Kosslyn, S. M., \& SQuire, L. R. (1992). Form specific visual priming in the right cerebral hemisphere. Journal of $E x$ perimental Psychology: Learning, Memory, \& Cognition, 18, 492-508.

Palmeri, T. J., Goldinger, S. D., \& Pisoni, D. B. (1993). Episodic encoding of voice attributes and recognition memory for spoken words. Journal of Experimental Psychology: Learning, Memory, \& Cognition, 19, 309-328.

RaJARAM, S, \& RoEDiger, H. L., III (1993). Direct comparison of four implicit memory tests. Journal of Experimental Psychology: Learning, Memory, \& Cognition, 19, 765-776.

Roediger, H. L., III, \& Blaxton, T. A. (1987). Effects of varying modality, surface features, and retention interval on priming in wordfragment completion. Memory \& Cognition, 15, 379-388.

RoEdiger, H. L., III, \& MCDermotr, K. B. (1993). Implicit memory in normal human participants. In H. Spinnler \& F. Boller (Eds.), Handbook of neuropsychology (Vol. 8, pp. 63-131). Amsterdam: Elsevier.

SCHACTER, D. L. (1994). Priming and multiple memory systems: Perceptual mechanisms of implicit memory. In D. L. Schacter \& E. Tulving (Eds.), Memory systems 1994 (pp. 233-268). Cambridge, MA: MIT Press.

Schacter, D. L., \& Buckner, R. L. (1998). Priming and the brain. Neuron, 20, 185-195.

SCHACTER, D. L., Chiv, C.-Y. P., \& OChSNER, K. N. (1993). Implicit memory: A selective review. Annual Review of Neuroscience, 16, 159-182.

SCHACTER, D. L., \& ChURCh, B. A. (1992). Auditory priming: Implicit and explicit memory for words and voices. Journal of Experimental Psychology: Learning, Memory, \& Cognition, 18, 915-930.

Schacter, D. L., Church, B. [A.], \& Bolton, E. (1995). Implicit memory in amnesic patients: Impairment of voice-specific priming. Psychological Science, 6, 20-25.

Schacter, D. L., Church, B. A., \& Osowiecki, D. M. (1994). Auditory priming in elderly adults: Impairment of voice-specific implicit memory. Memory, 2, 295-323.

SHEFFERT, S. M. (1998). Voice-specificity effects on auditory word priming. Memory \& Cognition, 26, 591-598.

SheFfert, S. M., \& Fowler, C. A. (1995). The effects of voice and visible speaker change on memory for spoken words. Journal of Memory \& Language, 34, 665-685.

SQuiRE, L. R. (1994). Declarative and nondeclarative memory: Multiple brain systems supporting learning and memory. In D. L. Schacter \& E. Tulving (Eds.), Memory systems 1994 (pp. 203-231). Cambridge, MA: MIT Press.

SRINIVAS, K. (1993). Perceptual specificity in nonverbal priming. Journal of Experimental Psychology: Learning, Memory, \& Cognition, 19, 582-602.

SRINIVAS, K. (1995). Representation of rotated objects in explicit and implicit memory. Journal of Experimental Psychology: Learning. Memory, \& Cognition, 21, 1019-1036.

Stuart, G. P., \& Jones, D. M. (1995). Priming the identification of environmental sounds. Quarterly Journal of Experimental Psychology, 48A, 741-761.

STUART, G. P., \& JONES, D. M. (1996). From auditory image to auditory percept: Facilitation through common processes? Memory \& Cognition, 24, 296-304.

TENPENNy, P. L. (1995). Abstractionist versus episodic theories of repetition priming and word identification. Psychonomic Bulletin \& Review, 2, 339-363.

Vaidya, C. J., Gabrieli, J. D. E., Verfaellie, M., Fleischman, D., \& ASKARI, N. (1998). Font-specific priming following global amnesia and occipital lobe damage. Neuropsychology, 12, 183-192.

WARREN, C., \& Morton, J. (1982). The effects of priming on picture recognition. British Journal of Psychology, 73, 117-129.

\section{NOTES}

1. A number of other scoring criteria that differed in the leniency with which responses were accepted as correct were tried, but they all led to identical results. For example, a more liberal criterion would accept events that could have produced a sound that is highly similar to the target as correct, accepting bomb, explosion, lightning, rainstorm, and 
thunderstorm as correct for the sound thunder. A more conservative criterion would only accept thunder or thunderstorm as correct.

2. A combined $2 \times 2 \times 2$ ANOVA was performed to compare perceptual priming and explicit recall more directly, with encoding (semantic vs. nonsemantic) and type of test (adjusted cued recall vs. adjusted priming score) as between-subjects variables and stimulus form (same exemplar vs. different exemplar) as a within-subjects variable. This ANOVA revealed a significant encoding effect $\left[F(1,68)=6.37, M S_{\mathrm{e}}=\right.$ $0.058]$, a significant test effect $\left[F(1,68)=115.3, M S_{\mathrm{e}}=0.058\right]$, and a significant effect of stimulus form $\left[F(1,68)=27.5, M S_{\mathrm{e}}=0.039\right]$. None of the interaction effects, however, was significant (all $F \mathrm{~s}<1$ ).

3. The pattern of results from the subject analyses was identical to that obtained in analyses by items in this and all the subsequent experiments; thus, only the analyses by subjects are reported.

4. A combined $2 \times 2 \times 2$ ANOVA on the priming scores and adjusted recall scores revealed a significant encoding effect $[F(1,68)=$
7.19, $\left.M S_{e}=0.054\right]$, a significant test effect $\left[F(1,68)=79.6, M S_{e}=\right.$ $0.054]$, and a significant effect of stimulus form $\left[F(1,68)=23.0, M S_{\mathrm{e}}=\right.$ $0.012]$. More important, the two-way interaction between encoding and test was now significant $\left[F(1,68)=8.07, M S_{\mathrm{e}}=0.054\right]$, indicating that encoding affected cued recall, but not priming. No other effect approached significance (all $F \mathbf{s}<1$ ).

5 . A combined $2 \times 2 \times 2$ ANOVA on priming and adjusted recognition score indicated that there was a depth of processing effect in sound recognition but not in SIIN: The encoding $\times$ test interaction was significant $\left[F(1,68)=5.52, M S_{\mathrm{e}}=0.062\right]$. Changing exemplar between study and test adversely affected recognition, but not SIIN: The stimulus form $\times$ test interaction was significant $[F(1,68)=5.91$, $\left.M S_{\mathrm{e}}=0.016\right]$. The main effects of test $\left[F(1,68)=90.4, M S_{\mathrm{e}}=0.062\right]$ and stimulus form $\left[F(1,68)=14.1, M S_{\mathrm{e}}=0.016\right]$ were both significant. None of the remaining effects was significant (all $F_{\mathrm{s}}<2.40, p \mathrm{~s}>$ .12).

APPENDIX A

Individual Statistics of Environmental Sound Stimuli Used in Experiments 1 and 2

\begin{tabular}{|c|c|c|c|c|c|c|c|}
\hline Sound Name & Experiment & Origin & $\begin{array}{l}5-\mathrm{sec} \\
\text { RMS }\end{array}$ & $\begin{array}{l}\text { 5-sec } \\
\text { Peak }\end{array}$ & $\begin{array}{l}\text { Crest } \\
\text { Factor }\end{array}$ & $\begin{array}{c}5-\sec \\
\text { ID }^{*}\end{array}$ & $\begin{array}{c}1-\mathrm{sec} \\
\text { ID }\end{array}$ \\
\hline Glass breaking & 1 & DES: vol. 7 track 41 & 65.5 & 68.3 & 3.80 & 0.84 & 0.63 \\
\hline Glass breaking & 1 & S: $1014-51-01$ & 63.9 & 71.0 & 6.23 & 0.75 & 0.25 \\
\hline Car horns & 2 & ASE: vol. 2 track 34 & 64.0 & 62.9 & 2.41 & 0.95 & 0.68 \\
\hline Car horns & 2 & $S: 1003-30-05$ & 64.2 & 71.0 & 6.00 & 1.00 & 0.85 \\
\hline Coins dropping & 1,2 & DES: vol. 7 track 49 & 66.5 & 71.0 & 4.59 & 0.84 & 0.63 \\
\hline Coins dropping & 1,2 & HEPE: $16-37$ & 61.9 & 71.0 & 7.84 & 1.00 & 0.70 \\
\hline Dot matrix printer & 1,2 & $S: 1007-68-01$ & 64.1 & 71.0 & 6.06 & 0.85 & 0.45 \\
\hline Dot matrix printer & 1,2 & ASE: vol. 1 track 69 & 65.3 & 71.0 & 5.30 & 1.00 & 0.58 \\
\hline Footsteps & 1,2 & TR: track 37 & 58.4 & 71.0 & 11.67 & 0.84 & 0.11 \\
\hline Footsteps & 1,2 & $S: 1013-14-01$ & 58.3 & 71.0 & 11.84 & 0.95 & 0.65 \\
\hline Heartbeats & 1 & ASE: vol. 3 track 92 & 72.0 & 71.0 & 2.47 & 0.85 & 0.40 \\
\hline Heartbeats & 2 & HEPE:14-66 & 72.3 & 71.0 & 2.35 & 0.85 & 0.40 \\
\hline Heartbeats & 1,2 & $S: 1016-17-01$ & 73.3 & 71.0 & 2.14 & 0.60 & 0.15 \\
\hline Helicopter hovering & 1,2 & ASE: vol. 2 track 78 & 71.9 & 69.2 & 1.99 & 1.00 & 0.58 \\
\hline Helicopter hovering & 1,2 & S: $1014-19-02$ & 64.3 & 71.0 & 5.89 & 0.85 & 0.50 \\
\hline Kettle begins whistling & 1,2 & TR: track 30 & 71.6 & 71.0 & 2.56 & 0.84 & 0.50 \\
\hline Kettle begins whistling & 1,2 & $S: 1015-37-01$ & 66.8 & 71.0 & 4.40 & 0.90 & 0.20 \\
\hline Sharpening a knife & 1,2 & ASE: vol. 1 track $3 \mathrm{~A}$ & 56.7 & 71.0 & 14.31 & 0.74 & 0.53 \\
\hline Sharpening a knife & 1,2 & $S: 1015-13-05$ & 62.6 & 71.0 & 7.16 & 0.70 & 0.45 \\
\hline Videogame in progress & 2 & S: $1023-06-01$ & 65.1 & 68.8 & 4.18 & 0.95 & 0.70 \\
\hline Videogame in progress & 2 & AF: track 39 & 72.9 & 70.0 & 1.95 & 1.00 & 0.53 \\
\hline Ping pong game & 1,2 & ASE: vol. 3 track 48 & 58.2 & 71.0 & 11.99 & 0.84 & 0.21 \\
\hline Ping pong game & 1,2 & S: $1022-49-02$ & 57.6 & 71.0 & 12.84 & 0.70 & 0.35 \\
\hline Dialing rotary phone & 1,2 & ASE: vol. 1 track 65 & 64.0 & 71.0 & 6.13 & 1.00 & 0.85 \\
\hline Dialing rotary phone & 1,2 & $S: 1025-64-02$ & 59.8 & 71.0 & 9.89 & 0.45 & 0.05 \\
\hline Sawing wood & 1,2 & ASE: vol. 1 track 56 & 59.1 & 71.0 & 10.80 & 0.89 & 0.58 \\
\hline Sawing wood & 1 & $S: 1009-03-01$ & 63.5 & 71.0 & 6.46 & 0.50 & 0.20 \\
\hline Sawing wood & 2 & S.1009-18-01 & 66.0 & 71.0 & 4.85 & 0.80 & 0.55 \\
\hline Squeaky gate closing & 1,2 & ASE: vol. 1 track 63 & 62.9 & 67.6 & 4.73 & 0.60 & 0.05 \\
\hline Squeaky gate closing & 1,2 & $S: 1009-64-01$ & 63.9 & 70.8 & 6.03 & 0.80 & 0.30 \\
\hline Manual stapler stapling & 1 & GW: vol. $3 / 4$ track 41 & 55.8 & 71.0 & 15.85 & 0.37 & 0.05 \\
\hline Manual stapler stapling & $i$ & $S: 1022-14-01$ & 59.5 & 71.0 & 10.30 & 0.38 & 0.05 \\
\hline Tennis match & 2 & ASE: vol. 3 track 49 & 62.3 & 71.0 & 7.45 & 0.95 & 0.30 \\
\hline Tennis match & 2 & $\mathrm{~S}: 1026-31-01$ & 56.7 & 71.0 & 14.14 & 0.75 & 0.25 \\
\hline Thunder & 1,2 & ASE: vol. 3 track 90 & 74.1 & 69.1 & 1.54 & 0.80 & 0.38 \\
\hline Thunder & 1,2 & HEPE:05-09 (sec $15 \rightarrow)$ & 70.2 & 71.0 & 3.03 & 0.85 & 0.60 \\
\hline Clock ticking & 2 & ASE: vol. 1 track 39 & 61.9 & 71.0 & 7.83 & 0.95 & 0.45 \\
\hline Clock ticking & 2 & $S: 1005-69-01$ & 57.9 & 71.0 & 12.32 & 1.00 & 0.47 \\
\hline Flushing toilet & 2 & ASE: vol. 1 track $14 \mathrm{C}$ & 68.0 & 68.9 & 3.03 & 0.95 & 0.63 \\
\hline Flushing toilet & 2 & $S: 1015-18-02$ & 61.8 & 71.0 & 7.92 & 0.95 & 0.70 \\
\hline Brushing teeth & 1,2 & ASE: vol. 1 track $16 \mathrm{~A}$ & 63.0 & 71.0 & 6.88 & 0.79 & 0.42 \\
\hline
\end{tabular}


APPENDIX A (Continued)

\begin{tabular}{|c|c|c|c|c|c|c|c|}
\hline Brushing teeth & 1,2 & $S: 1015-10-01$ & 61.5 & 71.0 & 8.15 & 0.95 & 0.30 \\
\hline Vacuuming floor & 1,2 & ASE: vol. 1 track $32 \mathrm{~A}$ & 67.1 & 71.0 & 4.30 & 0.53 & 0.37 \\
\hline Vacuuming floor & 1,2 & $S: 1026-73-01$ & 65.7 & 71.0 & 5.02 & 0.70 & 0.45 \\
\hline Windchimes clinging & 1,2 & ASE: vol. 1 track 49 & 63.2 & 68.6 & 5.11 & 0.89 & 0.16 \\
\hline Windchimes clinging & 1,2 & HEPE: $19-39$ & 55.8 & 71.0 & 15.73 & 0.90 & 0.60 \\
\hline Open and close a door & 2 & S: $1003-39-0203$ & 58.5 & 71.0 & 11.54 & 0.94 & 0.45 \\
\hline Open and close a door & 2 & $S: 1027-33-01-34-01$ & 61.3 & 71.0 & 8.36 & 0.95 & 0.85 \\
\hline Jack hammer & 2 & S: $1008-18-01$ & 68.4 & 71.0 & 3.70 & 0.90 & 0.15 \\
\hline Jack hammer & 2 & $S: 1008-19-01$ & 68.0 & 71.0 & 3.86 & 0.85 & 0.70 \\
\hline Tearing paper & 1 & S: $1014-47-0102$ & 61.3 & 71.0 & 8.36 & 0.85 & 0.35 \\
\hline Tearing paper & 1 & $S: 1014-47-03$ & 61.0 & 71.0 & 8.65 & 0.65 & 0.55 \\
\hline Sweeping floor & 1 & $S: 1014-59-01$ & 60.0 & 69.5 & 8.12 & 0.63 & 0.15 \\
\hline Sweeping floor & 1 & $S: 1014-64-01$ & 51.8 & 66.5 & 14.72 & 0.73 & 0.20 \\
\hline Opening a soda bottle & 2 & $S: 1015-03-02$ & 65.7 & 71.0 & 5.06 & 0.90 & 0.25 \\
\hline Opening a soda bottle & 2 & $\mathrm{~S}: 1015-05-02$ & 67.1 & 71.0 & 4.28 & 0.80 & 0.75 \\
\hline Morse code & 1 & $S: 1018-50-01$ & 65.1 & 63.1 & 2.16 & 0.65 & 0.15 \\
\hline Morse code & 1 & $S: 1018-51-01$ & 63.6 & 63.1 & 2.58 & 0.74 & 0.10 \\
\hline Motorcycle revving & 1,2 & $S: 1018-65-01$ & 66.5 & 70.3 & 4.27 & 0.90 & 0.30 \\
\hline Motorcycle revving & 1,2 & $S: 1018-71-01$ & 67.0 & 71.0 & 4.33 & 0.70 & 0.35 \\
\hline Typing on a typewriter & 2 & $S: 1022-17-01$ & 58.3 & 70.6 & 11.26 & 0.86 & 0.25 \\
\hline Typing on a typewriter & 2 & $S: 1022-18-01$ & 64.6 & 71.0 & 5.74 & 1.00 & 0.80 \\
\hline Starting a car & 2 & $S: 1027-26-01$ & 65.4 & 71.0 & 5.21 & 0.95 & 0.45 \\
\hline Starting a car & 2 & $S: 1027-27-01$ & 66.7 & 71.0 & 4.50 & 0.90 & 0.70 \\
\hline Wind blowing & 2 & $S: 1028-51-01$ & 66.7 & 68.6 & 3.40 & 0.38 & 0.30 \\
\hline Wind blowing & 2 & S:1028-55-01 & 66.2 & 71.0 & 4.74 & 0.38 & 0.30 \\
\hline
\end{tabular}

Note-Root-mean square (RMS) and peak levels are in units of dB SPL. AF, America's Funniest Sound Effects for Home Video [CD] (Hackensack, NJ: Essex Entertainment); ASE, J. Holzman, J. (Producer), Authentic sound effects [CD] (Vols. 1-3; New York: Elektra); DES, Dureco Sound Effects [CD] (Vols. 7-8; Munich: Dureco Weesp Holland); GW, SFX Sound Effects [CD] (Vols. 3.4-5.6; Fort Lauderdale, FL: Gateway Recording). HEPE, Hollywood Edge Premiere Edition Sound Effects Library [CD] (Vols. 1-20; Hollywood: Hollywood Edge). S, Sound Ideas Series 1000 Sound Effects Library [CD] (Vols. 1-28; Richmond Hill, ON, Canada: Sound Ideas). TR, R. Harding (Producer), 50 Plus Different Sound Effects (Burbank,CA: Total Recording of California). *Identification norms for 5-sec sound. †Identification norms for the 1-sec stems.

APPENDIX B

Individual Statistics of Environmental Sound Stimuli Used in Experiments 3 and 4

\begin{tabular}{|c|c|c|c|c|c|c|c|c|}
\hline Experiment & Sound Name & Origin & $\begin{array}{l}5-\mathrm{sec} \\
\text { RMS } \\
\end{array}$ & $\begin{array}{l}5 \text {-sec } \\
\text { Peak }\end{array}$ & $\begin{array}{c}5-\mathrm{sec} \\
\text { ID }\end{array}$ & $\begin{array}{c}\text { Experiment } 3 \\
\text { Noise } \\
\text { RMS* } \\
\end{array}$ & $\begin{array}{c}\text { Experiment } 3 \\
\text { SIIN } \\
\text { ID }\end{array}$ & $\begin{array}{c}\text { Experiment } 4 \\
\text { Noise } \\
\text { RMS } \dagger \\
\end{array}$ \\
\hline 3 & Open and close a car door & $\mathrm{S}: 1027-33-01-34-01$ & 58.51 & 74.32 & 0.94 & 65.81 & 0.50 & \\
\hline 3 & Open and close a car door & $\mathrm{S}: 1027-33-01-34-01$ & 61.32 & 74.32 & 0.95 & 68.50 & 0.33 & \\
\hline 3 & Thunder storm & ASE: vol. 3 track 90 & 74.07 & 72.39 & 0.80 & 74.10 & 0.33 & \\
\hline 3 & Thunder storm & HEPE:05-09 & 70.19 & 74.33 & 0.85 & 74.10 & 0.33 & \\
\hline 3 & Starting vacuum cleaner & ASE: vol. 1 track $32 \mathrm{~A}$ & 67.08 & 74.32 & 0.53 & 65.81 & 0.00 & \\
\hline 3 & Starting vacuum cleaner & $S: 1026-73-01$ & 65.72 & 74.31 & 0.70 & 65.81 & 0.00 & \\
\hline 4 & Glass breaking & DES: vol. 7 track 41 & 65.46 & 68.32 & 0.84 & 71.00 & & \\
\hline 4 & Glass breaking & S: $1009-29-0123$ & 64.54 & 70.87 & 0.95 & 69.06 & & \\
\hline 4 & One chime of doorbell & $S: 1005-27-03$ & 64.44 & 70.97 & 1.00 & 70.08 & & \\
\hline 4 & One chime of doorbell & $S: 1020-37-04$ & 59.07 & 67.65 & 1.00 & 71.00 & & \\
\hline 4 & Bowling ball hitting pins & $S: 1005-44-01$ & 63.70 & 71.01 & 1.00 & 81.46 & & \\
\hline 4 & Bowling ball hitting pins & $S: 1005-46-01$ & 64.37 & 71.01 & 0.94 & 71.00 & & \\
\hline 3,4 & 3 car horns & ASE: vol. 2 track 34 & 63.99 & 66.18 & 0.95 & 80.12 & 0.50 & 79.20 \\
\hline 3,4 & 3 car horns & $\mathrm{S}: 1003-30-05$ & 64.16 & 74.28 & 1.00 & 78.96 & 0.00 & 78.04 \\
\hline 3,4 & Coin dropped into a glass & DES: vol. 7 track 49 & 66.49 & 74.29 & 0.84 & 72.41 & 0.00 & 71.50 \\
\hline 3,4 & Coin dropped onto table & HEPE: $16-37$ & 61.87 & 74.31 & 1.00 & 69.06 & 0.00 & 68.15 \\
\hline 3,4 & Dot matrix printer printing & $S: 1007-68-01$ & 64.10 & 74.31 & 0.85 & 67.90 & 0.17 & 67.90 \\
\hline 3,4 & Dot matrix printer printing & ASE: vol. 1 track 69 & 65.28 & 74.33 & 1.00 & 72.41 & 0.00 & 67.90 \\
\hline 3,4 & One person's footsteps & TR: track 37 & 58.41 & 74.32 & 0.84 & 69.59 & 0.17 & 68.62 \\
\hline 3,4 & One person's footsteps & S:1013-14-01 & 58.28 & 74.31 & 0.95 & 69.59 & 0.67 & 68.62 \\
\hline 3,4 & 3 moderately fast heartbeats & HEPE: $14-66$ & 72.33 & 74.33 & 0.85 & 81.46 & 0.67 & 81.46 \\
\hline 3,4 & 3 moderately fast heartbeats & S:1016-17-01 & 73.32 & 74.33 & 0.60 & 81.46 & 0.00 & 81.46 \\
\hline 3,4 & Helicopter hovering & ASE: vol. 2 track 78 & 71.91 & 72.46 & 1.00 & 81.46 & 0.00 & 80.54 \\
\hline
\end{tabular}


APPENDIX B (Continued)

\begin{tabular}{|c|c|c|c|c|c|c|c|c|}
\hline 3,4 & Helicopter hovering & $S: 1014-19-02$ & 64.31 & 74.27 & 0.85 & 74.10 & 0.00 & 73.18 \\
\hline 3,4 & Kettle begins to whistle & TR: track 30 & 71.60 & 74.33 & 0.84 & 73.50 & 0.50 & 72.58 \\
\hline 3,4 & Kettle begins to whistle & S: $1015-37-01$ & 66.83 & 74.27 & 0.90 & 73.50 & 0.33 & 72.58 \\
\hline 3,4 & Sharpening a knife & ASE: vol. 1 track $3 \mathrm{~A}$ & 56.65 & 74.33 & 0.74 & 65.81 & 0.00 & 64.89 \\
\hline 3,4 & Sharpening a knife & $S: 1015-13-05$ & 62.65 & 74.31 & 0.70 & 66.56 & 0.00 & 65.65 \\
\hline 3,4 & Ping pong game in progress & ASE: vol. 3 track 48 & 58.19 & 74.32 & 0.84 & 67.26 & 0.00 & 66.34 \\
\hline 3,4 & Ping pong game in progress & S: $1022-49-02$ & 57.58 & 74.32 & 0.70 & 69.06 & 0.00 & 68.15 \\
\hline 3,4 & Dialing rotary phone & ASE: vol. 1 track 65 & 64.02 & 74.33 & 1.00 & 71.00 & 0.00 & 70.08 \\
\hline 3,4 & Dialing rotary phone & $S: 1025-64-02$ & 59.84 & 74.31 & 0.45 & 66.56 & 0.00 & 65.65 \\
\hline 3,4 & Sawing wood & S: $1009-04-01$ & 66.04 & 74.31 & 1.00 & 67.26 & 0.00 & 67.26 \\
\hline 3,4 & Sawing wood & S. $1009-05-01$ & 61.76 & 74.31 & 1.00 & 71.00 & 0.00 & 71.00 \\
\hline 3,4 & Squeaky gate slowly closing & ASE: vol. 1 track 63 & 62.88 & 70.93 & 0.63 & 67.90 & 0.18 & 66.99 \\
\hline 3,4 & Squeaky gate slowly closing & $S: 1009-64-01$ & 63.93 & 74.10 & 0.80 & 71.00 & 0.18 & 70.08 \\
\hline 3,4 & Tennis match & ASE: vol. 3 track 49 & 62.31 & 74.33 & 0.95 & 74.10 & 0.67 & 73.18 \\
\hline 3,4 & Tennis match & $S: 1026-31-01$ & 56.74 & 74.31 & 0.75 & 67.90 & 0.50 & 66.99 \\
\hline 3,4 & Clock ticking & ASE: vol. 1 track 39 & 57.94 & 74.32 & 0.95 & 70.08 & 0.33 & 69.17 \\
\hline 3,4 & Clock ticking & S: $1005-69-01$ & 61.86 & 74.30 & 1.00 & 74.10 & 0.33 & 73.18 \\
\hline 3,4 & Flushing toilet & ASE: vol. 1 track $14 \mathrm{C}$ & 67.97 & 72.17 & 0.95 & 72.94 & 0.00 & 72.02 \\
\hline 3,4 & Flushing toilet & $S: 1015-18-02$ & 61.76 & 71.01 & 0.95 & 71.00 & 0.33 & 71.00 \\
\hline 3,4 & Brushing teeth & ASE: vol. 1 track $16 \mathrm{~A}$ & 63.00 & 74.32 & 0.79 & 67.26 & 0.00 & 66.34 \\
\hline 3,4 & Brushing teeth & $S: 1015-10-01$ & 61.52 & 74.31 & 0.95 & 68.50 & 0.17 & 67.59 \\
\hline 3,4 & Videogame in progress & AF: track 39 & 72.94 & 73.32 & 1.00 & 81.46 & 0.00 & 81.46 \\
\hline 3,4 & Videogame in progress & $S: 1023-06-01$ & 65.13 & 72.11 & 0.95 & 81.46 & 0.00 & 80.54 \\
\hline 3,4 & Clings from windchime & ASE: vol. 1 track 49 & 63.16 & 71.89 & 0.89 & 67.26 & 0.00 & 66.34 \\
\hline 3,4 & Clings from windchime & HEPE: $19-39$ & 55.82 & 74.31 & 0.90 & 67.26 & 0.33 & 66.34 \\
\hline 3,4 & Jack hammer & S:1008-18-01 & 68.39 & 74.31 & 0.90 & 71.00 & 0.17 & 71.00 \\
\hline 3,4 & Jack hammer & $S: 1008-19-01$ & 68.04 & 74.32 & 0.85 & 75.44 & 0.17 & 75.44 \\
\hline 3,4 & Open a bottle of soda & $S: 1015-03-02$ & 65.67 & 74.32 & 0.90 & 77.02 & 0.67 & 77.02 \\
\hline 3,4 & Open a bottle of soda & $S: 1015-05-02$ & 67.12 & 74.31 & 0.80 & 72.94 & 0.17 & 72.94 \\
\hline 3,4 & Motorcycle revving & $S: 1018-71-01$ & 67.01 & 74.30 & 0.70 & 75.44 & 0.50 & 74.52 \\
\hline 3,4 & Motorcycle revving & $S: 1018-65-01$ & 66.46 & 73.64 & 0.90 & 74.10 & 0.67 & 73.18 \\
\hline 3,4 & Typing on a typewriter & $S: 1022-17-01$ & 58.27 & 73.85 & 0.86 & 68.50 & 0.33 & 67.59 \\
\hline 3,4 & Typing on a typewriter & S.1022-18-01 & 64.56 & 74.31 & 1.00 & 65.81 & 0.00 & 64.89 \\
\hline 3,4 & Starting a car & $S: 1027-26-01$ & 65.41 & 74.31 & 0.95 & 71.00 & 0.67 & 70.08 \\
\hline 3,4 & Starting a car & S:1027-27-01 & 66.68 & 74.31 & 0.90 & 74.10 & 0.18 & 70.08 \\
\hline 3,4 & Wind blowing & $S: 1028-55-01$ & 66.23 & 74.31 & 0.60 & 72.94 & 0.33 & 72.94 \\
\hline 3,4 & Wind blowing & S: $1028-51-01$ & 66.67 & 71.85 & 1.00 & 74.10 & 0.50 & 74.10 \\
\hline
\end{tabular}

Note-AF, America's Funniest Sound Effects for Home Video [CD] (Hackensack, NJ: Essex Entertainment); ASE, J. Holzman (Producer), Authentic Sound Effects [CD] (Vols. 1-3; New York: Elektra); DES, Dureco Sound Effects [CD] (Munich: Dureco Weesp Holland); HEPE, Hollywood Edge Premiere Edition Sound Effects Library [CD] (Vols. 1-20; Hollywood: The Hollywood Edge); S, Sound Ideas Series 1000 Sound Effects Library [CD] (Vols. 1-28; Richmond Hill, ON, Canada: Sound Ideas). TR, R. Harding (Producer), 50 Plus Different Sound Effects (Burbank, CA: Total Recording of California). *The individual root-mean square level in dB SPL for the noise mask used in Experiment 3. TThe individual RMS level for the noise mask used in Experiment 4.

(Manuscript received August 17, 1998;

revision accepted for publication November $25,1999$. 